\title{
The new clinical trials on pharmacological treatment in pulmonary arterial hypertension
}

\author{
N. Galiè, A. Manes, A. Branzi
}

\begin{abstract}
The new clinical trials on pharmacological treatment in pulmonary arterial hypertension. N. Galiè, A. Manes, A. Branzi. (C) ERS Journals Ltd 2002.

ABSTRACT: Past medical therapy for pulmonary arterial hypertension included the use of calcium-channel antagonists in acute vasoreactive subjects and oral anticoagulants and continuous intravenous administration of epoprostenol in the more severe cases. Recently, the thromboxane inhibitor terbogrel, the prostacyclin analogues treprostinil, beraprost and iloprost, and the endothelin receptor antagonist bosentan have been tested in clinical trials in $>1,100$ patients.

Except for terbogrel, all compounds improved the mean exercise capacity by different degrees, as assessed by the 6-min walk test. In the evaluation of the clinical relevance of exercise capacity improvements, additional elements need to be considered, such as baseline functional class and concomitant favourable effects on combined clinical events (including hospitalisations, mortality and rescue therapies), quality of life and haemodynamics. No trials have shown effects on mortality, as the study protocols were not designed for assessing this end-point. Each new compound presents side-effects that are unpredictable in the individual patient and require appropriate attention upon treatment initiation and maintenance.

These new therapeutic options will be available in the near future and will allow tailoring of the most appropriate treatment to the single patient, according to an individualised benefit-to-risk ratio.
\end{abstract}

Eur Respir J 2002; 20: 1037-1049.

Institute of Cardiology, University of Bologna, Bologna, Italy.

Correspondence: N. Galiè

Istituto di Cardiologia

Università di Bologna

via Massarenti, 9

40138-Bologna

Italy

Fax: 39051344859

E-mail: n.galie@bo.nettuno.it

Keywords: Beraprost

bosentan

endothelin

iloprost

prostacyclin

treprostinil

Received: June 272002

Accepted after revision: July 12002
Pulmonary arterial hypertension $(\mathrm{PAH})$ is defined, according to the 1998 World Health Organization Classification [1], as a group of diseases characterised by virtually identical obstructive pathological changes of the pulmonary microcirculation [2] and by a favourable response to the long-term administration of prostacyclin $[3,4]$. PAH includes primary pulmonary hypertension (PPH) [5] and pulmonary hypertension associated with various conditions, such as collagen vascular diseases [6], congenital systemic-topulmonary shunts [7], portal hypertension [8] and human immunodeficiency virus (HIV) infection [9]. All these conditions share comparable clinical pictures and the outcome is usually related to a progressive increase of pulmonary vascular resistance leading to right ventricular failure and death $[5,10]$.

Survival of patients with PAH is reduced according to haemodynamic impairment [11], New York Heart Association (NYHA) functional class [11], exercise capacity as assessed by 6-min walk test [12] and aetiology [13]. The median life expectancy from the time of diagnosis in patients with $\mathrm{PPH}$ before the prostacyclin era was $2.8 \mathrm{yrs}$ [11] and mean age at the time of death in patients with pulmonary hypertension associated with simple congenital systemic-topulmonary shunts was $32.5 \pm 14.6$ yrs [14].

The history of the treatments for PAH patients shows that progress has been slow in the past few decades (table 1). The initial therapeutic approaches were initiated just after the first modern description of the disease in the 1950s by Dresdale et al. [15] and Wood [16] with empiric attempts to reduce pulmonary artery pressure by the acute administration of vasodilators. The approach of acutely testing the vasoreactivity of pulmonary circulation was subsequently accomplished by the use of many compounds, including tolazoline, acetylcholine, diazoxide, hydralazine, phentolamine, isoproterenol, nitrates, verapamil, nifedipine and diltiazem [17].

In the 1970s and early 1980s several small and uncontrolled long-term trials with various vasodilators (including sublingual isoprenline, diazoxide and hydralazine) $[18,19]$ tested the hypothesis that vasoconstriction was the principal mechanism for 
Table 1.-History of treatments for pulmonary arterial hypertension

\begin{tabular}{ll}
\hline Year & Treatment \\
\hline $1950-1980$ & $\begin{array}{l}\text { Empirical/various vasodilators } \\
\text { for acute vasoreactivity testing } \\
\text { (tolazoline, acetylcholine, } \\
\text { diazoxide, hydralazine, } \\
\text { phentolamine, isoproterenol, } \\
\text { nitrates, verapamil, nifedipine } \\
\text { and diltiazem) } \\
\text { Uncontrolled trials on long-term } \\
\text { vasodilator treatments } \\
\text { Oral anticoagulants } \\
\text { High-dose calcium channel } \\
\text { antagonists (in acute } \\
\text { vasoreactivity tests responders) } \\
\text { Lung, heart/lung transplantation } \\
\text { Intravenous epoprostenol prostacyclin } \\
\text { Balloon atrial septostomy } \\
\text { New compounds }\end{array}$ \\
\hline $1980-$ &
\end{tabular}

initiating and perpetuating PAH [16]. Even if the results were considered encouraging [18, 19], the design and small sample size of these studies prevented the assessment of the real impact of the treatments on exercise capacity and prognosis.

From the mid 1980s to the early 1990s the results of uncontrolled long-term studies on the favourable effects of oral anticoagulant treatment $[20,21]$ and of high doses of the calcium-channel antagonists nifedipine and diltiazem (in the minority of patients who responded to acute vasoreactivity tests) [21] were published. Since then, these two therapies have been considered as the main elements of the "conventional treatment" for $\mathrm{PAH}$, which also includes diuretics and digoxin in case of overt right heart failure and supplemental oxygen in case of hypoxaemia.

In the same period, the therapeutic option of heart/lung or lung transplantation became available, although the shortage of organ donation limited the number of patients able to benefit from these treatments [22].

The 1990s have witnessed the development of the continuous intravenous administration of epoprostenol (prostacyclin), the efficacy of which has been demonstrated in several unblinded controlled clinical trials [23-25]. This form of therapy was defined "nonconventional" because of the cumbersome modality of administration, which requires a tunnelised catheter and portable infusion pump [3]. An interventional procedure, the balloon atrial septostomy, was also proposed in this period and studies on a small series of treated patients were published, showing favourable results [26].

Recently, there has been an extraordinary effort by the scientific community involved in PAH that has leaded to the completion of six blinded controlled clinical trials involving $>1,100$ patients (table 2).

The new compounds that were tested in these studies are the thromboxane inhibitor terbogrel [27], the prostacyclin analogues treprostinil (subcutaneous) [28], beraprost (oral) [29] and iloprost (inhaled) [30], and the endothelin receptor antagonist bosentan $[31,32]$.

The purpose of this article is to review and compare these controlled clinical trials and to provide preliminary insights into the future utilisation of these treatments in clinical practice.

Table 2. - Controlled clinical trials in patients with pulmonary arterial hypertension (PAH): patients number, designs and primary end-points

\begin{tabular}{|c|c|c|c|c|c|c|}
\hline & \multicolumn{6}{|c|}{ Trial [ref.] } \\
\hline & $\begin{array}{c}\text { Terbogrel } \\
{[27]}\end{array}$ & $\begin{array}{c}\text { Treprostinil } \\
{[28]}\end{array}$ & $\begin{array}{c}\text { Bosentan: pilot } \\
\text { [31] }\end{array}$ & $\begin{array}{c}\text { BREATHE-1 } \\
{[32]}\end{array}$ & $\begin{array}{c}\text { ALPHABET } \\
{[29]}\end{array}$ & $\begin{array}{l}\text { AIR } \\
{[30]}\end{array}$ \\
\hline \multicolumn{7}{|l|}{ Patients $n$} \\
\hline Total & 71 & 469 & 33 & 213 & 130 & 203 \\
\hline Placebo & 25 & 236 & 11 & 69 & 65 & 102 \\
\hline Active & 46 & 233 & 21 & $144^{\#}$ & 65 & 101 \\
\hline Drug & Terbogrel & Treprostinil & Bosentan & Bosentan & Beraprost & Iloprost \\
\hline $\begin{array}{l}\text { Route of } \\
\text { administration }\end{array}$ & Oral & Subcutaneous & Oral & Oral & Oral & Inhaled \\
\hline $\begin{array}{l}\text { Daily } \\
\quad \text { administrations } \mathrm{n}\end{array}$ & 2 & Continuous & 2 & 2 & 4 & $6-9$ \\
\hline $\begin{array}{l}\text { Duration of blinding } \\
\text { phase months }\end{array}$ & 3 & 3 & 3 & 4 & 3 & 3 \\
\hline $\begin{array}{l}\text { Open-label } \\
\text { extension }\end{array}$ & No & Yes & Yes & Yes & Yes & Yes \\
\hline $\begin{array}{l}\text { Primary } \\
\text { end-points }\end{array}$ & 6-min walk & 6-min walk & 6-min walk & 6-min walk & 6-min walk & $\begin{array}{c}\text { 6-min walk+ } \\
\text { NYHA }^{+}\end{array}$ \\
\hline $\begin{array}{l}\text { Secondary } \\
\text { end-points }\end{array}$ & Haemodynamics & Haemodynamics & Haemodynamics & & Haemodynamics & Haemodynamics \\
\hline Substudies & & & & Echocardiogram & & \\
\hline
\end{tabular}

BREATHE-1: Bosentan Randomised trial of Endothelin Antagonist Therapy for PAH; ALPHABET: Arterial Pulmonary Hypertension and Beraprost European Trial; AIR: Aerosolized Iloprost Randomised study; NYHA: New York Heart Association. ${ }^{\#}: 74$ assigned to the dose of $125 \mathrm{mg}$ b.i.d. and 70 to the dose of $250 \mathrm{mg}$ b.i.d.; ${ }^{\natural}$ : additional 3 months in one-third of the patients; ${ }^{+}$: combined end-point of an improvement in NYHA functional class and a $>10 \%$ improvement in 6 -min walk. 


\section{Thromboxane inhibition}

Endothelial cells modulate vascular smooth muscle cell activity by producing vasodilators/antimitotics, such as prostacyclin and nitric oxide (NO), and vasoconstrictors/mitogens, such as thromboxane $\mathrm{A}_{2}$ and endothelin-1 (ET-1). An increase in 24-h excretion of a thromboxane $\mathrm{A}_{2}$ metabolite (which is also a potent stimulus for platelet aggregation) and reduced excretion of a prostacyclin metabolite has been demonstrated in PAH patients [33]. These findings represent a rationale for the use of drugs such as terbogrel that can inhibit thromboxane $\mathrm{A}_{2}$ production and increase prostacyclin levels.

\section{Terbogrel study}

Terbogrel is an orally active potent thromboxane receptor antagonist and thromboxane synthetase inhibitor in normal humans. Furthermore, by inhibiting thromboxane synthesis, it appeared to shift the common precursor endoperoxide substrates used in the formation of both thromboxane and prostacyclin towards prostacyclin synthesis.

The effects of terbogrel were tested in a multicentre, randomised, placebo-controlled, 12-week study in NYHA class II and III PPH patients [27]. Although the planned enrolment was 135 patients, the study was halted after only 71 patients had been randomised, due to the unforeseen side-effect of leg pain, which occurred almost exclusively in terbogrel-treated patients. Leg pain resolved after drug discontinuation without any apparent residual damage and its pathogenesis is unknown. In addition, several investigators reported that terbogrel administration caused an increase in the International Normalised Ratio (INR), despite reduced dose levels of warfarin. Only 52 patients completed the 12-week study, and only 22 patients $(31 \%)$ were fully compliant with the study medication. The leg pain confounded the primary end-point of walking distance. Using an intention-to-treat analysis, there was no improvement in 6-min walk distance or in haemodynamics in terbogrel-treated patients. However, terbogrel was effective from a pharmacological standpoint, reducing thromboxane metabolites by up to $98 \%(\mathrm{p}<0.0001)$, with a modest but statistically insignificant $(39 \%)$ rise in prostacyclin metabolites.

\section{Prostacyclin analogues}

Prostacyclin is an endogenous substance produced by vascular endothelium that has vasodilating, antiplatelet aggregation and antiproliferative effects [34]. The rationale for the administration of prostacyclin in PAH patients is based on the demonstration of several changes of its metabolic pathways in patients and in experimental models of pulmonary hypertension [35]. In fact, a reduction of prostacyclin urinary metabolites and an increase of the thromboxane $\mathrm{A}_{2}$ urinary metabolites have been shown in patients with PPH [33]. Moreover, prostacyclin synthase expression is reduced in pulmonary arteries of patients with $\mathrm{PAH}$ [36], and endothelial cells cultured from pulmonary arteries of calves with hypoxia-induced pulmonary hypertension produce a reduced amount of prostacyclin [35].

Prostacyclin has a short half-life in the circulation (3-5 min) and is rapidly converted into stable breakdown products or metabolites. This explains why prostacyclin needs to be administered by a continuous intravenous route by means of infusion pumps. Therapy with continuous intravenous epoprostenol (synthetic salt of prostacyclin) has been shown to improve symptoms and prognosis in NYHA functional class III and IV patients with different types of PAH [23-25, 37-39]. However, epoprostenol is instable at room temperature, requires permanent intravenous catheters and portable pumps and is associated with several side-effects and potentially serious complications. For these reasons, alternatives to intravenous prostacyclin have been sought and this has led to the use of analogues that can be administered subcutaneously (treprostinil), orally (beraprost sodium) or by inhalation (iloprost) [40].

\section{Treprostinil study}

Treprostinil is a tricyclic benzidene analogue of epoprostenol, with sufficient chemical stability to be administered at ambient temperature in a physiological solution. These characteristics allow the administration of the compound by intravenous as well as by subcutaneous routes. Microinfusion pumps and small subcutaneous catheters, similar to those used for the administration of insulin in diabetic patients, can accomplish the latter modality of administration. This avoids all the problems linked to a permanent central venous line, such as infections, and the management of the system is much simpler. In a preliminary acute study on 12 patients with severe congestive heart failure, intravenous treprostinil induced haemodynamic changes very similar to those of epoprostenol [41]. The acute effect of subcutaneous treprostinil was compared to that of intravenous treprostinil in 25 patients with PPH and a comparable reduction of pulmonary vascular resistance of $\sim 20 \%$ was observed with both modalities of administration [42]. The apparent halflife of the compound was $27 \mathrm{~min}$ when administered intravenously and 58-83 min when administered subcutaneously. A pilot, randomised study on the chronic administration of treprostinil compared to placebo was completed in 26 patients with PPH, and, after 8 weeks, a reduction in pulmonary vascular resistance and an increase in functional capacity were shown in the treated group [43].

The efficacy of treprostinil in PAH patients has been tested in the largest worldwide study ever performed in this condition: 470 patients with NYHA class II, III and IV PPH and PAH associated with congenital heart disease and connective tissue diseases were enrolled in a 12-week controlled clinical trial [28]. The treatment effect (between treatment group difference) in median 6-min walking distance was $16 \mathrm{~m}(\mathrm{p}=0.006)$. Disease aetiology did not show significant interaction with the change in exercise capacity. The highest exercise improvement was 
observed in patients who were more compromised at baseline and in subjects who could tolerate an upper quartile dose (increase of $36.1 \pm 10 \mathrm{~m}$ from baseline in patients with a dose of $>13.8 \mathrm{ng} \cdot \mathrm{kg}^{-1} \cdot \mathrm{min}^{-1}$ ).

Improvements were also observed in clinical scores, Borg dyspnoea index and the physical dimension score of the Minnesota Living with Heart Failure Questionnaire of quality of life. Cardiopulmonary haemodynamic parameters, including right atrial pressure, mean pulmonary artery pressure and cardiac index, also improved. Event-free (death and hospitalisation) survival occurred in $94 \%$ of treprostinil versus $88 \%$ of placebo patients ( $\mathrm{p}=0.05$, unpublished data). Infusionsite pain was the most common side-effect of treprostinil, leading to discontinuation of the treatment in $8 \%$ of cases and limiting dose increase in an additional proportion of patients. Overall mortality was $3 \%$ and no difference was detected among treatment groups.

\section{Beraprost study}

Beraprost sodium is the first chemically stable and orally active prostacyclin analogue [44]. It is absorbed rapidly in fasting condition, peak concentration is reached after $30 \mathrm{~min}$ and elimination half-life is 35-40 min after single oral administration. When administered at the beginning of the meal, peak concentration is smaller and half-life is prolonged. In experimental studies, beraprost sodium has been shown to exert a protective effect on the development of monocrotaline-induced pulmonary hypertension [45]. Uncontrolled and retrospective experiences in patients with $\mathrm{PPH}$ have preliminarily shown that long-term oral treatment with beraprost sodium improves haemodynamics [46] and prognosis [47].

The first randomised, placebo-controlled study on beraprost in PAH was performed in 13 centres in six European countries (Arterial Pulmonary Hypertension and Beraprost European Trial (ALPHABET)) [29]. In this 12-week trial, 130 NYHA class II and III PAH patients with different aetiologies were enrolled, including PPH and PAH associated with connective tissue diseases, HIV infection, portal hypertension and congenital systemic-to-pulmonary shunts. Beraprost was administered orally four times a day at the highest tolerated dose and the treatment effect in mean 6-min walking distance was $25 \mathrm{~m}$. Borg dyspnoea index also improved. In this trial, no interaction was detected between baseline functional class and exercise improvement, while a different result was shown with regard to aetiology. In fact, the treatment effect in patients with $\mathrm{PPH}$ was $45 \mathrm{~m}$, whereas no significant changes were observed in the exercise capacity of subjects with the associated conditions. It is not clear whether this finding was linked to the tolerated doses of beraprost sodium that were substantially lower in patients with associated PAH forms compared to patients with PPH for unknown reasons. In fact, post hoc analysis showed that exercise capacity was increased mainly in patients who could tolerate a dose of $>80 \mu \mathrm{g}$ q.i.d. (unpublished data). Interestingly, the exercise capacity of placebo-treated patients with PPH decreased after 12 weeks, while in PAH, associated conditions remained unchanged. The beraprost-treated patients showed nonstatistically significant trends in the improvement of cardiopulmonary haemodynamics. Side-effects linked to systemic vasodilatation were frequent in the initial titration period and were reduced in the maintenance phase. Overall mortality was $1.5 \%$ and no difference was detected among treatment groups. No difference was detected in the rate of hospitalisation.

\section{Iloprost study}

Iloprost is a chemically stable prostacyclin analogue that can be used for intravenous, oral and inhaled administration. Continuous intravenous administration of iloprost appears to be as effective as epoprostenol in patients with PAH [48, 49], even though the experience with iloprost is more limited. Intermittent intravenous administration of iloprost has been attempted in cases with PAH associated with connective tissue diseases, but only the results of single cases have been reported [50].

The preliminary results on the effects of the acute administration of iloprost by inhalation in patients with PAH were reported in 1996 [51]. After a single inhalation of iloprost, a reduction of $10-20 \%$ of mean pulmonary artery pressure was observed and lasted for $60-120 \mathrm{~min}$. The acute administration of inhaled iloprost seems to be superior to the inhalation of 40 parts per million of NO in reducing pulmonary vascular resistance in PPH patients [52]. The short duration of action of inhaled iloprost means that frequent inhalations (6-12 times daily) are required to obtain a continuous effect in long-term treatments. Several uncontrolled studies have shown that inhaled iloprost exerts long-term haemodynamic, clinical and exercise improvements in PAH patients [53, 54]. In addition, in a group of patients with pulmonary hypertension and lung fibrosis, the acute administration of inhaled iloprost caused marked pulmonary vasodilatation with maintenance of gas exchange and systemic arterial pressure [55], showing a possible usefulness in this subset.

The first randomised, placebo-controlled study on inhaled iloprost in PAH (Aerosolized Iloprost Randomised study (AIR study)) was performed in 37 centres in eight European countries: 204 NYHA class III and IV PAH patients [30] were enrolled in a 12-week trial. Subjects with $\mathrm{PPH}, \mathrm{PAH}$ associated with connective tissue disease and inoperable chronic thromboembolic pulmonary hypertension were included. Daily repetitive iloprost inhalations (6-9 times, $2.5-5 \mu \mathrm{g} \cdot \mathrm{day}^{-1}$ ) were compared to placebo inhalation; the primary end-point was a combination of an improvement in NYHA functional class and a $>10 \%$ improvement in 6-min walk test at week 12 . The combined clinical end-point was met by $16.8 \%$ of iloprost versus $4.9 \%$ of placebo patients $(\mathrm{p}=0.007)$, without inhomogeneity over subgroups. The treatment effect on the 6-min walking distance was $36.4 \mathrm{~m}$ in favour of iloprost for all patients $(\mathrm{p}<0.01)$ and $57 \mathrm{~m}$ for PPH. Premature termination of the study, mostly due to deterioration, occurred in $4.0 \%$ of 
iloprost (including one death) versus $13.7 \%$ of placebo patients (including four deaths) $(\mathrm{p}=0.024)$. Overall, mortality was $2.5 \%$. Haemodynamics deteriorated in placebo patients while pulmonary vascular resistance improved in iloprost-treated subjects in pre-inhalation conditions. The acute inhalation induced a significant improvement in pulmonary artery pressure and cardiac output that lasted for about $60 \mathrm{~min}$. Further significant treatment effects included improvements in NYHA class $(\mathrm{p}=0.032)$, Mahler Dyspnoea Transition Index $(p=0.015)$ and EuroQol Visual Analogue Scale $(p=0.016)$. Adverse events reported more frequently for iloprost were flushing of the skin, jaw pain (transient and mild), and syncope, which was more frequently rated serious but was not associated with clinical deterioration.

\section{Endothelin receptor antagonism}

Increased plasma levels of ET-1, a vasoconstrictor and mitogen polypeptide produced by the endothelial cells have been reported in both experimental models and human PAH [56, 57]. It is not clear whether overexpression of ET-1 is a marker or a mediator of PAH. In patients with PPH, ET-1 plasma levels are inversely related to cardiac output and directly related to right atrial pressure and pulmonary vascular resistance [57]. In addition, elevated plasma levels of ET-1 in the same group identify a subset of patients with the worst prognosis [58]. Moreover, an elevated grade of ET-1-like immunoreactivity has been identified in almost all sections of pulmonary vascular bedincluded plexiform lesions, suggesting that the local production of ET-1 may contribute to the pathogenesis of PPH [59]. All these changes represent a strong rationale for attempting the antagonism of ET-1 effects.

The leading mechanism to antagonise ET-1 effects is the direct blockade of ET-1 receptors, which has been achieved by both peptide and nonpeptide drugs [60]. Two pharmacologically and molecularly distinct endothelin receptors subtypes have been identified: ETA and ETB. Both receptors are abundant in vascular smooth muscle cells and their stimulation produces vasoconstriction and proliferation. ETB receptors are predominant in vascular endothelial cells, where their stimulation favours ET-1 clearance and induces the production of $\mathrm{NO}$ and prostacyclin. The latter physiological negative feedback mechanism aims to protect against excessive activation of the endothelin system. ET-1 receptor antagonists prevent and reverse pathological and haemodynamic changes in experimental models of both hypoxiaand monocrotaline-induced pulmonary hypertension [61]. The favourable effects observed in experimental models have led to clinical trials in patients with PAH.

\section{Bosentan studies}

The orally active dual ET-1 (ETA and ETB) receptor antagonist bosentan has been tested in two double-blind, placebo-controlled studies in patients with PPH or PAH associated with connective tissue diseases. In the first pilot study, 33 NYHA class III patients were randomised 2:1 to receive either $125 \mathrm{mg}$ b.i.d. of bosentan or placebo [31]. After 12 weeks, a treatment effect of $76 \mathrm{~m}$ in favour of bosentan was observed in 6-min walking distance and the difference was maintained after 20 weeks. An improvement in right atrial pressure, cardiac index, mean pulmonary artery pressure and pulmonary vascular resistance was also found. Clinical end-points, such as Borg dyspnoea index, NYHA functional class and clinical worsening, also improved in actively treated patients. Increases in plasma levels of aminotransferases were seen in two patients assigned to bosentan, but the levels returned to normal without discontinuation or change of dose.

In the larger Bosentan Randomised trial of Endothelin Antagonist Therapy for PAH (BREATHE-1), study 213 NYHA class III and IV patients were randomised $1: 1: 1$ to receive placebo or $62.5 \mathrm{mg}$ of bosentan twice daily for 4 weeks, followed by either bosentan $125 \mathrm{mg}$ b.i.d. or $250 \mathrm{mg} \mathrm{b.i.d.} \mathrm{for} \mathrm{a} \mathrm{minimum} \mathrm{of} 12$ weeks [32]. At week 16, patients treated with bosentan improved their 6-min walking distance; the mean difference between the placebo and bosentan groups was $44 \mathrm{~m}$ (95\% confidence interval $21-67 \mathrm{~m}, \mathrm{p}<0.001)$. Although both bosentan dosages induced a significant treatment effect, the placebo-corrected improvement was more pronounced for the $250 \mathrm{mg}$ b.i.d. than for the $125 \mathrm{mg}$ b.i.d. dosage ( $+54 \mathrm{~m}$ and $+35 \mathrm{~m}$, respectively). However, no dose response for efficacy could be ascertained. Although a similar treatment effect was achieved in patients with PPH and in those with PAH associated with scleroderma, bosentan improved the walking distance from baseline in the PPH patients $(+46 \mathrm{~m}$ in the bosentan group versus $-5 \mathrm{~m}$ in the placebo group), whereas it prevented walk distance deterioration in the scleroderma patients $(+3 \mathrm{~m}$ in the bosentan group versus $-40 \mathrm{~m}$ in the placebo group). Bosentan also improved the Borg dyspnoea index and World Health Organization functional class, and, above all, increased the time to clinical worsening. Abnormal hepatic function was found to be dose-dependent. Increases in hepatic aminotransferases of at least eight times the normal upper limit occurred in two patients $(2.6 \%)$ in the $125 \mathrm{mg}$ b.i.d. group and five times $(7.1 \%)$ the normal upper limit in the $250 \mathrm{mg}$ b.i.d. group. Overall mortality was $2.8 \%$ and no difference among groups was detected.

An echocardiographic substudy was performed in 85 patients enrolled in 13 centres. Several echocardiographic and Doppler parameters related to $\mathrm{PAH}$ were improved in bosentan-treated patients, including Doppler-derived cardiac index $\left(+0.4 \mathrm{~L} \cdot \mathrm{min}^{-1} \cdot \mathrm{m}^{-2}, \mathrm{p}=\right.$ 0.007), Tei index, right and left ventricle dimensions and pericardial effusion score [62].

\section{General comments on the trials}

The need for controlled trials as definitive prove of efficacy and safety in clinical medicine is supported by the recent experiences with the rare disease PAH [40]. In fact, a drug with a sound rationale, such as the thromboxane $\mathrm{A}_{2}$ inhibitor terbogrel, can fail to show 
clinical benefit due to unpredictable side-effects that can only be identified and analysed appropriately in the rigorous mainframe of a multicentre study [27].

\section{Placebo effect}

The analysis of placebo-treated groups in the various trials can allow a better understanding of the natural history of PAH patients on conventional treatment and may give insights into clinical practice.

A significant part of the treatment effect (the difference between treatment group and placebo group in mean changes) observed in the recent studies is linked to a deterioration of placebo-treated subjects. Even though the severity of PAH patients is well known, it has been quite surprising to find a worsening of functional capacity as well as of haemodynamics and echocardiographic and Doppler parameters as early as 12-16 weeks [28-32, 62].

However, a detailed analysis of patients' exercise performance changes may show a more complex picture. In fact, the Kaplan-Meier plot of 6-min walk distance changes from baseline performed in the large patient population of the treprostinil study showed that $32 \%$ of patients in the placebo group actually increased exercise capacity from baseline by $20 \mathrm{~m}$ after 12 weeks (fig. 1). In contrast, $40 \%$ of patients of the same group reduced exercise capacity by $20 \mathrm{~m}$ after 12 weeks. This information would not be seen if only the mean data, which made no overall change to exercise capacity in the placebo group $(0 \mathrm{~m})$, were analysed. Interestingly, $43 \%$ of the treprostinil-treated patients had an increased exercise performance of $\geqslant 20 \mathrm{~m}$ and the difference in the proportion of patients who improved on active

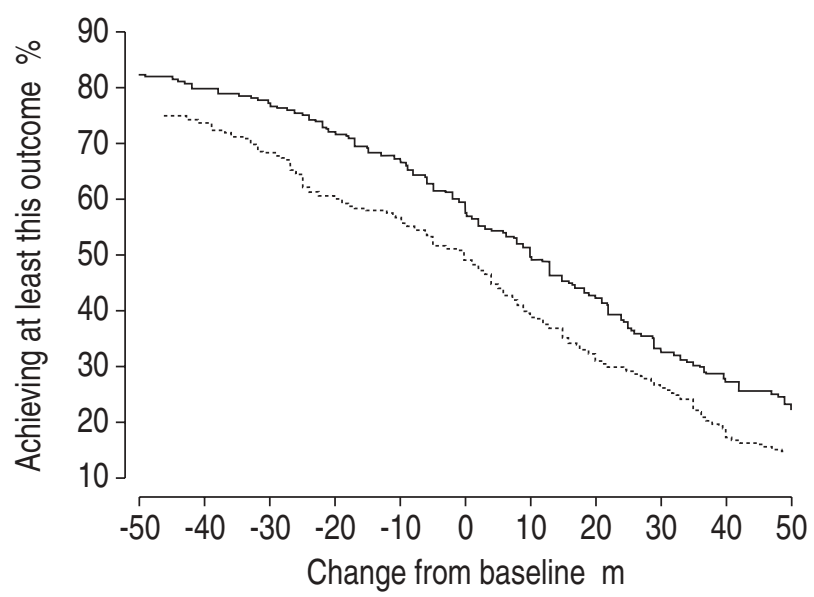

Fig. 1.-Kaplan-Meier plot of 6-min walk distance changes from baseline to week 12 in the patient population of the treprostinil study (placebo: ---; treprostinil-treated patients: -) [29]. An increase of $\geqslant 20 \mathrm{~m}$ from baseline to week 12 was observed in $32 \%$ of patients in the placebo group. In contrast, $40 \%$ of patients of the same group had a $20 \mathrm{~m}$ reduction in exercise capacity after 12 weeks. Forty-three per cent of the treprostinil-treated patients had an increased exercise performance of $20 \mathrm{~m}$ and the difference in the proportion of patients who improved on active treatment as compared to placebo $(\sim 11 \%)$ was similar over the entire spectrum of changes from baseline. treatment compared to placebo $(\sim 11 \%)$ was similar over the entire spectrum of changes from baseline.

These observations highlight the importance of a close clinical follow-up of PAH patients, which should perhaps include serial assessments of 6-min walking distance and echocardiogram to identify the subgroup with a tendency toward quicker worsening. This is particularly desirable in $\mathrm{PPH}$ patients who appear to show a higher rate of deterioration than some associated PAH conditions, such as cardiac congenital shunts [28, 29]. Moreover, a treatment that is able to prevent deterioration or produce only a slight increase in functional capacity can be considered of clinical utility when compared to a progressive and inexorable worsening as observed in a proportion of untreated subjects.

A consistent placebo effect, defined as a mean overall improvement in functional capacity, was observed in almost all trials in the first exercise test performed after baseline (usually after 4-6 weeks). The subsequent mean deterioration, as compared to baseline values, was detected in the following exercise tests performed after $12-16$ weeks. These findings therefore suggest that a real initial improvement in exercise capacity needs to be confirmed with additional successive assessments.

\section{Design and baseline comparisons}

The trials with the new compounds present similarities and differences.

The study design (double blind, randomised, placebocontrolled), duration and end-points were comparable (table 2). All studies, with the exception of the bosentan studies, used an active drug:placebo 1:1 randomisation procedure. In the pilot study, an active drug:placebo 2:1 randomisation ratio was adopted, while in the BREATHE-1 study, patients were equally randomised into three groups, one taking placebo and two taking different dosages of the active drug. It is unclear whether different randomisation procedures had some influence on the final results.

The duration of the studies ranged from 12-16 weeks and, in the BREATHE-1 study only, an additional period of blinded evaluation of 12 weeks was performed in one-third of the patients.

The primary end-point was exercise capacity as assessed by 6-min walking distance in all trials except for the AIR study, in which a combination of exercise capacity and NYHA functional class improvement was utilised.

Haemodynamics was one of the secondary endpoints in all studies except for BREATHE-1, in which an echocardiographic substudy was performed.

The sample size of the studies was quite different (table 2), varying from 33-496 patients, while the mean age was more uniform, ranging from 45-51 yrs.

The majority of patients included, ranging from 51 to $100 \%$, were NYHA functional class III (table 3). NYHA class II patients were predominantly enrolled in the terbogrel $(51 \%)$ and ALPHABET studies $(51 \%)$, while they were a minority in the treprostinil trial $(11 \%)$. NYHA functional class IV patients were largely 
Table 3.-Controlled clinical trials in patients with pulmonary arterial hypertension (PAH): clinical and functional characteristics and aetiology at baseline

\begin{tabular}{|c|c|c|c|c|c|c|}
\hline & \multicolumn{6}{|c|}{ Trial [ref.] } \\
\hline & $\begin{array}{c}\text { Terbogrel } \\
{[27]}\end{array}$ & $\begin{array}{c}\text { Treprostinil } \\
{[28]}\end{array}$ & $\begin{array}{c}\text { Bosentan: pilot } \\
{[31]}\end{array}$ & $\begin{array}{c}\text { BREATHE-1 } \\
\text { [32] }\end{array}$ & $\begin{array}{c}\text { ALPHABET } \\
{[29]}\end{array}$ & $\begin{array}{l}\text { AIR } \\
{[30]}\end{array}$ \\
\hline Age mean & 47 & 45 & 51 & 47 & 45 & 52 \\
\hline $\mathrm{M}: \mathrm{F} \%$ & $22: 78$ & 19:81 & $12: 88$ & $21: 79$ & $38: 62$ & $33: 67$ \\
\hline \multicolumn{7}{|l|}{$\begin{array}{l}\text { NYHA functional } \\
\text { class } \%\end{array}$} \\
\hline II & 49 & 11 & & & 49 & \\
\hline III & 51 & 82 & 100 & 91 & 51 & 59 \\
\hline IV & & 7 & & 9 & & 41 \\
\hline $\begin{array}{l}\text { 6-min walk } \\
\text { distance mean } \mathrm{m}\end{array}$ & 393 & 327 & 358 & 335 & 372 & 324 \\
\hline \multicolumn{7}{|l|}{ Aetiology $\% \#$} \\
\hline $\mathrm{PPH}$ & 100 & 58 & 85 & 70 & 48 & 54 \\
\hline $\mathrm{CTD}^{\bullet}$ & & 19 & 15 & 30 & 7 & 17 \\
\hline CHD & & 24 & & & 21 & \\
\hline СТЕРН & & & & & & 28 \\
\hline HIV & & & & & 7 & \\
\hline P-PH & & & & & 16 & \\
\hline
\end{tabular}

BREATHE-1: Bosentan Randomised trial of Endothelin Antagonist Therapy for PAH; ALPHABET: Arterial Pulmonary Hypertension and Beraprost European Trial; AIR: Aerosolized Iloprost Randomised study; M: male; F: female; NYHA: New York Heart Association; PPH: primary pulmonary hypertension; CTD: connective tissue disease; CHD: congenital heart disease (congenital systemic-to-pulmonary shunts); CTEPH: chronic thromboembolic pulmonary hypertension; HIV: human immunodeficiency virus; P-PH: porto-pulmonary hypertension. ${ }^{\#}$ : sum of $\%$ may not be $100 \%$ because of rounding to the nearest unit, 0.5 is rounded to the upper unit; " the majority of CTD were due to scleroderma.

enrolled in the AIR study (42\%), with a small percentage in the treprostinil $(7 \%)$ and BREATHE-1 studies $(9 \%)$. Nevertheless, in the latter studies, the mean baseline walking distances (table 3) were remarkably similar (324, 327 and $335 \mathrm{~m}$, respectively), showing that different criteria for the definition of NYHA functional class IV may have been applied in the AIR study compared to the treprostinil and BREATHE-1 trials. In contrast, in the studies in which a significant percentage of NYHA class II patients were included, such as the terbogrel and ALPHABET studies, the baseline exercise capacity was higher (393 and $372 \mathrm{~m}$, respectively) than in the other trials.

One of the most striking differences between studies is the inclusion of various aetiologies for PAH (table 3). In fact, the ALPHABET study was the only study in which almost all types of PAH were included, while the terbogrel study was the most selective as only PPH patients were enrolled. In the bosentan trials, only subjects with PPH and PAH associated with connective tissue diseases were included. In addition to these two aetiologies, patients with congenital systemicto-pulmonary shunts were enrolled in the treprostinil study and patients with inoperable chronic thromboembolic pulmonary hypertension were enrolled in the AIR study.

Interestingly, the principal baseline haemodynamic parameters showed small differences between the trials: right atrial pressure ranged from $8-10 \mathrm{mmHg}$, pulmonary artery pressure from $54-61 \mathrm{mmHg}$ and cardiac index from $2.3-2.4 \mathrm{mmHg}$ (table 4). However, the haemodynamic comparisons need to take into account the heterogeneity of the aetiologies, including the presence of patients with congenital systemic-topulmonary shunts and with portal hypertension that have specific haemodynamic findings, as in the treprostinil and ALPHABET trials.

In conclusion, similarities between these studies with regard to design, duration and end-points suggest

Table 4.-Controlled clinical trials in patients with pulmonary arterial hypertension (PAH): haemodynamics at baseline

\begin{tabular}{lcccccc}
\hline & \multicolumn{5}{c}{ Trial [ref.] } \\
\cline { 2 - 7 } & $\begin{array}{c}\text { Terbogrel } \\
{[27]}\end{array}$ & $\begin{array}{c}\text { Treprostinil } \\
{[28]}\end{array}$ & $\begin{array}{c}\text { Bosentan: pilot } \\
{[31]}\end{array}$ & $\begin{array}{c}\text { BREATHE-1 } \\
{[32]}\end{array}$ & $\begin{array}{c}\text { ALPHABET } \\
{[29]}\end{array}$ & $\begin{array}{c}\text { AIR } \\
{[30]}\end{array}$ \\
\hline $\begin{array}{c}\text { Haemodynamic parameters } \\
\text { Right atrial pressure mmHg }\end{array}$ & 8 & 10 & 10 & 10 & 8 & 9 \\
$\begin{array}{c}\text { Mean pulmonary artery } \\
\text { pressure mmHg }\end{array}$ & 55 & 61 & 55 & 54 & 59 & 53 \\
Cardiac index L·min & -1 \\
\hline
\end{tabular}

BREATHE-1: Bosentan Randomised trial of Endothelin Antagonist Therapy for PAH; ALPHABET: Arterial Pulmonary Hypertension and Beraprost European Trial; AIR: Aerosolized Iloprost Randomised study. 
that an appropriate comparison of the results can be performed. However, relevant differences, including the baseline NYHA functional class and the aetiology profiles, need to be taken into account in the comparative evaluation of these studies.

\section{Treatment effects comparison}

From a theoretical point of view, as no direct comparisons between treatments have been performed in a formal clinical trial, it may be difficult to evaluate the differences in the efficacy of the new compounds. In addition, the diversity in the characteristics of the inclusion criteria outlined above may further weaken any possible comparative assessment. However, even with these limitations, some insights can be gained from the combined analysis of the treatment effects of the studies.

With the exception of the terbogrel study, all compounds improved exercise capacity, as assessed by the 6 -min walking distance (table 5). The treatment effect ranged from a median difference of $16 \mathrm{~m}$ in the treprostinil study to $76 \mathrm{~m}$ in the pilot bosentan study. Interestingly, the largest study produced the smaller effect on exercise capacity while the smaller trial had the greater results. Besides the differences in the effects of the compounds on exercise capacity, other factors may contribute to these findings, including patient aetiology $(58 \%$ of $\mathrm{PPH}$ subjects in the treprostinil study compared to $85 \%$ in the pilot bosentan study), drug side-effects (such as infusion-site pain in the treprostinil study) and sample size (the smaller the trial the higher the possibility of extreme results). The importance of the aetiology is outlined by the fact that in almost all trials, patients with PPH have obtained a treatment effect appreciably higher than the other aetiologies (table 5), although a statistically significant difference was reported only in the ALPHABET study. The concomitance of additional conditions, such as congenital heart defects or multiorgan involvement in connective tissues diseases, HIV infection and portal hypertension, may have impaired the effect of the therapeutic interventions on exercise capacity.

Are the increases in 6-min walking distance observed in these studies clinically meaningful? This question is difficult to answer when analysing only the pure numerical increment in metres and considering that 6-min walking distance is correlated to survival [12]. Additional parameters, such as combined clinical events (hospitalisations, mortality, rescue therapies, etc.), clinical functional status, quality of life and haemodynamics, probably need to be evaluated to fully understand the real impact of these treatments.

Treprostinil therapy, which achieved the lowest treatment effect on exercise capacity, reduced combined clinical events and improved symptoms score, haemodynamics and the physical dimension of quality of life. Beraprost, which induced an intermediate increase of exercise capacity, did not change combined clinical events, haemodynamics and quality of life. However, less compromised patients were enrolled in this study, as shown by the low incidence of clinical events, including the lowest mortality rate of $1.5 \%$ compared to $2.8-3 \%$ in the other trials. The highest increase in exercise capacity was obtained in the bosentan studies, and there was also an improvement in NYHA functional class and haemodynamics and a reduction of clinical events. Besides an appreciable increment of exercise capacity, an improvement of clinical events, NYHA functional class, quality of life and haemodynamics (mainly postinhalation) were observed in the iloprost study (AIR study).

This comprehensive evaluation shows that each of these treatments have some "clinically relevant" effects on the specific study population (or subgroups) and the final balance probably requires an appropriate assessment in individual patients.

Interestingly, a dose/effect relationship has been observed in different trials. This effect was openly reported in the treprostinil study, which showed a clear increase of exercise capacity related to the higher tolerated doses of the drug [28]. Increased doses of beraprost in $\mathrm{PPH}$ patients have been suggested to

Table 5. - Controlled clinical trials in patients with pulmonary arterial hypertension (PAH): treatment effects

\begin{tabular}{|c|c|c|c|c|c|c|}
\hline & \multicolumn{6}{|c|}{ Trial [ref.] } \\
\hline & $\begin{array}{l}\text { Terbogrel } \\
{[27]}\end{array}$ & $\begin{array}{l}\text { Treprostinil } \\
{[28]}\end{array}$ & $\begin{array}{l}\text { Bosentan: pilot } \\
{[31]}\end{array}$ & $\begin{array}{c}\text { BREATHE-1 } \\
{[32,62]}\end{array}$ & $\begin{array}{c}\text { ALPHABET } \\
\text { [29] }\end{array}$ & $\begin{array}{l}\text { AIR } \\
{[30]}\end{array}$ \\
\hline \multicolumn{7}{|l|}{$\begin{array}{l}\text { Treatment effect on the } \\
\text { primary end-points } \\
\text { 6-min walk distance } \\
\text { mean change } m\end{array}$} \\
\hline Overall population & 0 & $16^{\#}$ & 76 & 44 & 25 & 36 \\
\hline PPH & 0 & $19^{\#}$ & 76 & 52 & 45 & 57 \\
\hline $\begin{array}{l}\text { Haemodynamic parameters } \\
\text { (overall population) }\end{array}$ & No change & Improved & Improved & Improved & No change & Improved $^{+}$ \\
\hline $\begin{array}{l}\text { Clinical events } \\
\text { (overall population) }\end{array}$ & Increased & Reduced & Reduced & Reduced & No change & Reduced \\
\hline
\end{tabular}

BREATHE-1: Bosentan Randomised trial of Endothelin Antagonist Therapy for PAH; ALPHABET: Arterial Pulmonary Hypertension and Beraprost European Trial; AIR: Aerosolized Iloprost Randomised study; PPH: primary pulmonary hypertension. ${ }^{\#}$ : median change; ${ }^{\text {: }}$ improvement in Doppler-derived cardiac index and other echocardiographic parameters. ${ }^{+}:$only pulmonary vascular resistance improved in pre-inhalation period and a more consistent improvement of other parameters is observed in postinhalation period. 
explain the better effect of the compound in this specific subset [29]. In the bosentan trial, the placebocorrected improvement was also more pronounced for the $250 \mathrm{mg}$ b.i.d. dose than for the $125 \mathrm{mg}$ b.i.d. dose, even if no dose/response relationship for efficacy could be ascertained [32]. A dose/effect relationship was not formally reported in the AIR study, even though an algorithm was used to try to maximise iloprost inhalation doses and the number of inhalations per day. Obviously, the dose/effect relationship may be relevant in clinical practice and needs to be taken into account in the evaluation of the final results of any treatment.

Further specific problems related to prostanoid pharmacokinetics (short half-life) are the modalities of administration: continuous (intravenous epoprostenol, subcutaneous treprostinil) or intermittent (oral beraprost and inhaled iloprost). In addition to any consideration of efficacy, as discussed above, the means of administration is relevant for aspects such as tolerance (the need to increase doses over time to maintain effects) and therapeutic gaps (prolonged intervals between doses, such as during the night). Even if the trials did not explore such topics, it can be argued that tolerance predominantly affects continuous treatments, while therapeutic gaps are observed mainly with intermittent therapies. The real impact of these phenomena on clinical practice and pharmacoeconomy is not clear and should be addressed in specific observational studies. In addition, the wellknown withdrawal effects of prostanoids that lead to abrupt deterioration of patients' conditions upon cessation of therapy, need to be outlined for safety reasons. If this effect is also shared by the endothelinreceptor antagonist bosentan, it is not clear but it is advisable that an appropriate down-titration protocol be used with strict clinical control in case this compound needs to be withdrawn.

Finally, an effect of mortality has not been observed in the trials with new compounds and there are several possible reasons for this. Up to now, the only clinical trial on PAH in which a reduction in mortality was obtained was a randomised open epoprostenol study in which a death rate of $20 \%$ over 12 weeks was observed in conventionally treated patients, compared to $0 \%$ in the epoprostenol group [24]. Since then, severe NYHA class III and IV patients that accept such relatively invasive treatment have been excluded from placebo-controlled studies for ethical reasons. This attitude has meant that less compromised patients have been enrolled in recent trials, in which mortality rates have ranged from $1.5-3.0 \%$ over the $12-16$ weeks of the study period. This reduced death rate combined with a relatively small sample size and short trial duration with a primary end-point of exercise capacity, are likely to have resulted in studies that lacked the power to detect any difference in mortality. Conversely, the favourable effects on 6-min walking distance and haemodynamics, which are both predictors of outcome [11, 12], could be considered as surrogate for mortality. The currently ongoing long-term, open-label studies' extension may provide further insights into the prognostic effect of the new compounds, even if the comparisons can only be made with historical controls.
The identification of the most effective treatment and the most appropriate drug dose in a single patient is a complex process that requires experience with all new treatments. It is obvious that such experience can only be collected in referral centres that have the facilities to follow-up a sufficient number of patients. Even though the new therapies have shown efficacy, it must be noted that, as yet, no cure for PAH has been identified and that the medical treatments still fail in a substantial proportion of subjects. The decisions to adopt interventional procedures like balloon atrial septostomy or to refer patients for lung transplantation remain important points. Therefore, it is critical that PAH patients are treated in experienced centres, even though the new therapeutic options appear less complex and are easier to administer than intravenous epoprostenol.

\section{Side-effect comparison}

Another important issue in the comparative evaluation of the new treatments is the relevance of the side-effects.

As previously stated, an important although reversible side-effect, i.e. leg pain, led to the premature discontinuation of the terbogrel study. Unfortunately, this problem resulted in the interruption of the clinical studies examining a relevant pathophysiological mechanism for $\mathrm{PAH}$, i.e. the thromboxane $\mathrm{A}_{2}$ pathway.

Pain at the site of subcutaneous injection is frequent in treprostinil therapy and can influence dosing and efficacy. Nevertheless, $>500$ patients are currently treated with treprostinil and recently the Food and Drug Administration has granted approval for this treatment in the USA in NYHA classes II, III and IV PAH. This shows that, even with side-effects, effective treatments are acceptable for the treatment of severe and life-threatening conditions. At present, different strategies, such as local anaesthetics or prolongation of catheter site permanence, are implemented in experienced centres to cope with site pain.

Side-effects of beraprost are mainly related to the rapid intestinal absorption of the drug and the peak plasma concentration. For these reasons, flushing, headache and sometimes hypotension are short lasting and are reduced upon administration after meals. These side-effects are reduced over time and become more acceptable during maintenance administration.

Iloprost side-effects are mainly linked to the burdensome need for frequent daily inhalations (from a minimum of six to a maximum of 12), which can reduce the interval between administrations by up to $2 \mathrm{~h}$. A particular phenomenon observed in the AIR study was the increased incidence of syncope episodes in the iloprost-treated patients compared to placebo. These events mainly occurred during exercise and some time after the previous inhalation, indicating that the therapeutic effect cannot cover the entire between-inhalation period. The increase of exercise capacity experienced by actively treated patients shortly after inhalation may not be maintained after several hours and the unconscious attempt to repeat the previous performance may lead to syncope. In 
fact, the increased incidence of fainting was not linked to additional signals of clinical deterioration.

The most frequent side-effect of bosentan treatment is a dose-dependent increase of liver transaminases. In the BREATHE-1 study, the global incidence of clinically relevant increases (eight times normal upper limits) was $9.7 \%$ but a permanent discontinuation was only needed in three cases $(2 \%)$. The dose-dependence of this side-effect has led to the suggestion that $125 \mathrm{mg} \mathrm{b.i.d}$. is the clinically preferable dose. Frequent checks of hepatic function are also advisable upon initiation of treatment or increase of doses.

It is important to note that the incidence of sideeffects with any treatment is unpredictable in the single patient. In the future it would be beneficial to try to identify clinical and/or biochemical characteristics that may suggest an increased occurrence of adverse reactions. Until then, the remarkable individual variability will require an adequate control of a patient when any treatment is initiated.

\section{Conclusions}

Recent clinical trials with novel compounds have produced a tremendous increase in both knowledge and therapeutic options in patients with PAH. Nevertheless, additional experience is needed to fully understand the real impact of the new treatments in day-by-day patient management. The following can be concluded from the comparative analysis of the trials. 1) The analysis of placebo-treated groups in the various trials has allowed a better understanding of the natural history of PAH. 2) The new trials have similar designs, durations and end-points, but relevant differences, including the baseline NYHA functional class and the aetiology profiles, need to be taken into account in the comparative evaluation of these studies. 3) Except for the terbogrel study, all compounds have improved the mean exercise capacity, as assessed by the 6-min walking test (table 5). 4) In the evaluation of the clinical relevance of exercise capacity improvements, additional elements need to be considered, such as baseline functional class and concomitant favourable effects on combined clinical events (including hospitalisations, mortality and rescue therapies), quality of life and haemodynamics. 5) The lack of effect on mortality can be explained by the study protocols that were not designed to assess this endpoint. 6) Each new compound presents unpredictable side-effects in individual patients and require appropriate attention upon treatment initiation and maintenance. 7) The availability of these new therapeutic options is of extreme importance in order to adapt the most appropriate treatment to the patient according, to an individualised benefit-to-risk ratio. 8) In this complex process of decision making, the role of expert pulmonary hypertension centres is essential in order to optimise the therapeutic strategy in each case. 9) As yet, no cure for PAH has been found, as available medical treatments still fail in a substantial proportion of patients and additional compounds need to be actively investigated.

\section{Insights for clinical practice}

The current therapeutic approach to patients with PAH will soon change remarkably. From a practical and regulatory point of view it needs to be stressed that the new compounds are currently in different phases of official approval processes.

Treprostinil has recently been approved by the Food and Drugs Administration in the USA for NYHA classes II, III and IV PAH. In Europe, an approval process is pending by the French Health Authority and by the European Agency (EMEA).

Beraprost has been approved in Japan for PAH patients and an approval process is pending by the French Health Authority.

Bosentan has been approved for the treatment of NYHA class III and IV PAH patients in the USA, Canada and Switzerland and preliminary approval has also been granted by EMEA.

Iloprost is available by private insurance reimbursement in Germany, Austria and Switzerland and an approval process by EMEA is pending.

The traditional treatment strategy for PAH includes oral anticoagulation in the absence of contraindication and diuretics in case of right heart failure and fluid retention. Some experts also suggest the addition of digoxin in the latter condition. All patients should undergo vasoreactivity tests to identify the minority (10-20\%) of patients that will benefit from chronic calcium channel blocker therapy. The current authors believe that this should be maintained after new treatments become available, as the identification of a subgroup of vasoreactive patients that present a good prognosis on a simple and low-cost treatment seems an advisable strategy.

\section{NYHA functional class $I$}

Patients with PAH in NYHA functional class I have not been included in the recent trials and no information is available on the benefit-to-risk ratio of the new compounds. In these cases, if the exercise capacity as assessed by 6-min walk $(>500 \mathrm{~m})$ and haemodynamics are satisfactory, a traditional approach and a "watchful waiting" strategy seem appropriate. Further studies are needed to clarify whether novel drugs are able to prevent the deterioration in this particular subset.

\section{NYHA functional class II}

Patients with PAH in NYHA functional class II have only been included in the treprostinil (11\%) and ALPHABET (49\%) studies (table 3 ). From a theoretical point of view, only these two treatments should be initiated in this group, and in the USA, the only drug approved for NYHA class II is treprostinil. Nevertheless, it may sometimes be difficult to differentiate between NYHA functional class II and III and additional information should be obtained via exercise tests and haemodynamics. As the orally active endothelin receptor antagonist bosentan is a simple and effective treatment, its use should be also considered if 
the objective measurements of functional capacity and right heart function show early signs of deterioration.

\section{NYHA functional class III}

Patients with NYHA functional class III have been included in all studies and all compounds have shown different degrees of effectiveness. Bosentan treatment seems to have the best combination of simplicity (b.i.d. oral administration) and efficacy, even if the incidence of liver function abnormalities requires a close followup. Beraprost is also an oral drug and may be used in patients that refuse the more burdensome route of prostanoid administration. Inhaled iloprost and subcutaneous treprostinil treatments are effective, even though they present some complexities linked to the number of inhalations, the infusion system and local pain. In these cases, the decision should be based on the local availability of the compound, on the single centre experience and on the preference of the patients. Obviously, if the first-tested prostanoid treatment is not effective or not tolerated an alternative route of administration should be attempted. The combination of bosentan and prostanoids is currently been investigated in a controlled clinical trial in patients requiring intravenous epoprostenol (BREATHE-2). The efficacy and safety of the combination of bosentan with other compounds would require specific studies in experienced centres.

In a single patient, an ideal result is reached if an improvement of one functional class is made and if the 6-min walking distance is increased by $\geqslant 450-500 \mathrm{~m}$.

\section{NYHA functional class IV}

Rescue treatment is required in NYHA class IV patients and the greatest experience has been with intravenous epoprostenol. In some centres inhaled iloprost has also been used as emergency treatment [53]. As mentioned above, the efficacy of the combination of epoprostenol with bosentan is currently under scrutiny. If patients remain in advanced NYHA class III or IV, additional measures need to be considered, such as balloon atrial septostomy and lung transplantation.

\section{Additional remarks}

In the near future, additional information on new compounds will be available.

A clinical trial on the ETA-selective endothelinreceptor antagonist sitaxsentan [63] has been performed on $180 \mathrm{PAH}$ patients in the USA and preliminary results will be available in autumn 2002 . Another study on the ETA-selective endothelin-receptor antagonist ambisentan (BSF208075) [64] is soon to begin in the USA and Europe.

As NO is synthesised from the amino acid L-arginine by NO-synthase [65], supplementation of L-arginine may have a beneficial effect in pulmonary hypertension. In a study of patients with pulmonary hypertension, intravenous administration of L-arginine has been shown to decrease pulmonary vascular resistance by increasing the endogenous production of NO [66]. In addition, in a placebo-controlled study it has been shown that 1-week supplementation of oral L-arginine to patients with PAH had a beneficial effect on haemodynamics and exercise capacity [67]. A clinical trial on the effects of the oral supplementation of L-arginine in $120 \mathrm{PAH}$ patients is currently ongoing in 15 centres worldwide (PHAST study).

Sildenafil is an orally active, potent and selective inhibitor of cyclic guanosine monophosphate (cGMP)specific phosphodiesterase type 5 (PDE-5), which is the predominant PDE isoenzyme in human corpora cavernosa. PDE-5 is selectively abundant in the pulmonary vasculature compared to systemic vessels, and in experimental models of pulmonary hypertension, sildenafil is able to reduce pulmonary artery pressure [68]. Many uncontrolled experiences on the favourable effects of sildenafil in PAH have recently been reported $[69,70]$. At the time of writing, a clinical trial on the effects of sildenafil in PAH was in an advanced phase of implementation.

The availability of various therapies has made the concepts of transition from a treatment to a different one and of the combination of diverse drugs possible.

Preliminary reports have shown that it is possible to switch patients from epoprostenol to treprostinil [71]. Obviously, transitions should only be performed in experienced centres. Other investigators have reported unpublished data on the transition of adult patients from intravenous epoprostenol to bosentan.

As mentioned above, a study on the combination of epoprostenol and bosentan (BREATHE-2) is ongoing on 33 PAH patients. Preliminary results will be available in autumn 2002.

Favourable effects have recently been reported with the combination of inhaled iloprost and oral sildenafil [72].

In the future, many other transitions and combinations will be possible with the increase of available treatments and it would be advisable to collect such experiences in registries in order to verify effects and to develop specific protocols.

\section{References}

1. Nomenclature Committee. Nomenclature and classification of pulmonary hypertension. Rich S, ed. Primary pulmonary hypertension: executive summary from the World Symposium - Primary Pulmonary Hypertension 1998, 25-27. World Health Organization, 1998. www5.who.int/cardiovascular-disease/main-cfm?s= 0006\# online.

2. Pietra GG, Edwards WD, Kay JM, et al. Histopathology of primary pulmonary hypertension. A qualitative and quantitative study of pulmonary blood vessels from 58 patients in the National Heart, Lung, and Blood Institute, Primary Pulmonary Hypertension Registry. Circulation 1989; 80: 1198-1206.

3. Galie N, Manes A, Branzi A. Medical therapy of pulmonary hypertension. The prostacyclins. Clin Chest Med 2001; 22: 529-537. 
4. Palevsky HI, Schloo BL, Pietra GG, et al. Primary pulmonary hypertension. Vascular structure, morphometry, and responsiveness to vasodilator agents. Circulation 1989; 80: 1207-1221.

5. Rubin LJ. Primary pulmonary hypertension. $N$ Engl J Med 1997; 336: 111-117.

6. MacGregor AJ, Canavan R, Knight C, et al. Pulmonary hypertension in systemic sclerosis: risk factors for progression and consequences for survival. Rheumatology (Oxford) 2001; 40: 453-459.

7. Brickner ME, Hillis LD, Lange RA. Congenital heart disease in adults. Second of two parts. $N$ Engl J Med 2000; 342: 334-342. (Published erratum appears in $N$ Engl J Med 2000; 342: 988.)

8. Herve $\mathrm{P}$, Lebrec D, Brenot $\mathrm{F}$, et al. Pulmonary vascular disorders in portal hypertension. Eur Respir $J$ 1998; 11: 1153-1166.

9. Petitpretz P, Brenot F, Azarian R, et al. Pulmonary hypertension in patients with human immunodeficiency virus infection. Comparison with primary pulmonary hypertension. Circulation 1994; 89: 2722 2727.

10. Galie N, Manes A, Uguccioni L, et al. Primary pulmonary hypertension: insights into pathogenesis from epidemiology. Chest 1998; 114: Suppl., 184S194 S.

11. D'Alonzo GE, Barst RJ, Ayres SM, et al. Survival in patients with primary pulmonary hypertension. Results from a national prospective registry. Ann Intern Med 1991; 115: 343-349.

12. Miyamoto $\mathrm{S}$, Nagaya $\mathrm{N}$, Satoh $\mathrm{T}$, et al. Clinical correlates and prognostic significance of six-minute walk test in patients with primary pulmonary hypertension. Comparison with cardiopulmonary exercise testing. Am J Respir Crit Care Med 2000; 161: 487-492.

13. Hopkins WE, Ochoa LL, Richardson GW, Trulock EP. Comparison of the hemodynamics and survival of adults with severe primary pulmonary hypertension or Eisenmenger syndrome. J Heart Lung Transplant 1996; 15: $100-105$.

14. Daliento L, Somerville J, Presbitero P, et al. Eisenmenger syndrome. Factors relating to deterioration and death. Eur Heart J 1998; 19: 1845-1855.

15. Dresdale DT, Schultz M, Michtom RJ. Primary pulmonary hypertension I. Clinical and hemodynamic study. Am J Med 1951; 11: 686-705.

16. Wood P. Primary pulmonary hypertension, with special reference to the vasoconstrictive factor. Br Heart $J$ 1958; 20: 557-565.

17. Weir EK, Rubin LJ, Ayres SM, et al. The acute administration of vasodilators in primary pulmonary hypertension. Experience from the National Institutes of Health Registry on Primary Pulmonary Hypertension. Am Rev Respir Dis 1989; 140: 1623-1630.

18. Reeves JT. Hope in primary pulmonary hypertension (editorial). N Engl J Med 1980; 302: 112-113.

19. Elkayam U. Vasodilator therapy in primary pulmonary hypertension (editorial). Chest 1981; 79: 253-254.

20. Fuster V, Steele PM, Edwards WD, Gersh BJ, McGoon MD, Frye RL. Primary pulmonary hypertension: natural history and the importance of thrombosis. Circulation 1984; 70: 580-587.

21. Rich S, Kaufmann E, Levy PS. The effect of high doses of calcium-channel blockers on survival in primary pulmonary hypertension. $N$ Engl J Med 1992; 327: 76-81.

22. Hosenpud JD, Bennett LE, Keck BM, Boucek MM, Novick RJ. The Registry of the International Society for Heart and Lung Transplantation: eighteenth Official Report - 2001. J Heart Lung Transplant 2001; 20: 805-815.

23. Rubin LJ, Mendoza J, Hood M, et al. Treatment of primary pulmonary hypertension with continuous intravenous prostacyclin (epoprostenol). Results of a randomized trial. Ann Intern Med 1990; 112: 485-491.

24. Barst RJ, Rubin LJ, Long WA, et al. A comparison of continuous intravenous epoprostenol (prostacyclin) with conventional therapy for primary pulmonary hypertension. The Primary Pulmonary Hypertension Study Group. N Engl J Med 1996; 334: 296-302.

25. Badesch DB, Tapson VF, McGoon MD, et al. Continuous intravenous epoprostenol for pulmonary hypertension due to the scleroderma spectrum of disease. A randomized, controlled trial. Ann Intern Med 2000; 132: 425-434.

26. Sandoval J, Gaspar J, Pulido T, et al. Graded balloon dilation atrial septostomy in severe primary pulmonary hypertension. A therapeutic alternative for patients nonresponsive to vasodilator treatment. $\mathrm{J} \mathrm{Am}$ Coll Cardiol 1998; 32: 297-304.

27. Langleben D, Christman BW, Barst RJ, et al. Effects of the thromboxane synthetase inhibitor and receptor antagonist terbogrel in patients with primary pulmonary hypertension. Am Heart $J$ 2002; 143: E4.

28. Simonneau G, Barst RJ, Galie N, et al. Continuous subcutaneous infusion of treprostinil, a prostacyclin analogue, in patients with pulmonary arterial hypertension. A double-blind, randomized, placebo-controlled trial. Am J Respir Crit Care Med 2002; 165: 800-804.

29. Galie N, Humbert M, Vachiery JL, et al. Effects of beraprost sodium, an oral prostacyclin analogue, in patients with pulmonary arterial hypertension: a randomised, double-blind placebo-controlled trial. J Am Coll Cardiol 2002; 39: 1496-1502.

30. Olschewski H, Simonneau G, Galie N, et al. Inhaled iloprost in severe pulmonary hypertension. $N$ Engl J Med 2002; 347: 322-329.

31. Channick RN, Simonneau G, Sitbon O, et al. Effects of the dual endothelin-receptor antagonist bosentan in patients with pulmonary hypertension: a randomised placebo-controlled study. Lancet 2001; 358: 1119 1123.

32. Rubin LJ, Badesch DB, Barst RJ, et al. Bosentan therapy for pulmonary arterial hypertension. $N \mathrm{Engl}$ $J$ Med 2002; 346: 896-903.

33. Christman BW, McPherson CD, Newman JH, et al. An imbalance between the excretion of thromboxane and prostacyclin metabolites in pulmonary hypertension. N Engl J Med 1992; 327: 70-75.

34. Moncada S, Gryglewski R, Bunting S, Vane JR. An enzyme isolated from arteries transforms prostaglandin endoperoxides to an unstable substance that inhibits platelet aggregation. Nature 1976; 263: 663-665.

35. Badesch DB, Orton EC, Zapp LM, et al. Decreased arterial wall prostaglandin production in neonatal calves with severe chronic pulmonary hypertension. Am J Respir Cell Mol Biol 1989; 1: 489-498.

36. Tuder RM, Cool CD, Geraci MW, et al. Prostacyclin synthase expression is decreased in lungs from patients with severe pulmonary hypertension. Am J Respir Crit Care Med 1999; 159: 1925-1932.

37. Rosenzweig EB, Kerstein D, Barst RJ. Long-term prostacyclin for pulmonary hypertension with associated congenital heart defects. Circulation 1999; 99: $1858-1865$. 
38. McLaughlin VV, Genthner DE, Panella MM, Hess DM, Rich S. Compassionate use of continuous prostacyclin in the management of secondary pulmonary hypertension: a case series. Ann Intern Med 1999; 130: 740-743.

39. Aguilar RV, Farber HW. Epoprostenol (prostacyclin) therapy in HIV-associated pulmonary hypertension. Am J Respir Crit Care Med 2000; 162: 1846-1850.

40. Galie N. Do we need controlled clinical trials in pulmonary arterial hypertension? Eur Respir J 2001; 17: $1-3$.

41. Patterson JH, Adams KF Jr, Gheorghiade M, et al. Acute hemodynamic effects of the prostacyclin analog 15AU81 in severe congestive heart failure. $A m J$ Cardiol 1995; 75: 26A-33A.

42. Gaine SP, Barst RJ, Rich S, et al. Acute hemodynamic effects of subcutaneous UT 15 in primay pulmonary hypertension. Am J Crit Care Med 1999; 159: A161.

43. McLaughlin V, Barst R, Rich S, et al. Efficacy and safety of UT-15, a prostacyclin analogue for primary pulmonary hypertension. Eur Heart $J$ 1999; 20: 486.

44. Nishio S, Kurumatani H. Pharmacological and clinical properties of beraprost sodium, orally active prostacyclin analogue. Nippon Yakurigaku Zasshi 2001; 117: 123-130.

45. Miyata M, Ueno Y, Sekine H, et al. Protective effect of beraprost sodium, a stable prostacyclin analogue, in development of monocrotaline-induced pulmonary hypertension. J Cardiovasc Pharmacol 1996; 27: 20-26.

46. Okano Y, Yoshioka T, Shimouchi A, Satoh T, Kunieda T. Orally active prostacyclin analogue in primary pulmonary hypertension. Lancet 1997; 349: 1365.

47. Nagaya N, Uematsu M, Okano Y, et al. Effect of orally active prostacyclin analogue on survival of outpatients with primary pulmonary hypertension. J Am Coll Cardiol 1999; 34: 1188-1192.

48. Higenbottam T, Butt AY, McMahon A, Westerbeck $\mathrm{R}$, Sharples L. Long-term intravenous prostaglandin (epoprostenol or iloprost) for treatment of severe pulmonary hypertension. Heart 1998; 80: 151-155.

49. Higenbottam TW, Butt AY, Dinh-Xaun AT, Takao M, Cremona G, Akamine S. Treatment of pulmonary hypertension with the continuous infusion of a prostacyclin analogue, iloprost. Heart 1998; 79: 175-179.

50. Mok MY, Tse HF, Lau CS. Pulmonary hypertension secondary to systemic lupus erythematosus: prolonged survival following treatment with intermittent low dose iloprost. Lupus 1999; 8: 328-331.

51. Olschewski H, Walmrath D, Schermuly R, Ghofrani A, Grimminger F, Seeger W. Aerosolized prostacyclin and iloprost in severe pulmonary hypertension. Ann Intern Med 1996; 124: 820-824.

52. Hoeper MM, Olschewski H, Ghofrani HA, et al. A comparison of the acute hemodynamic effects of inhaled nitric oxide and aerosolized iloprost in primary pulmonary hypertension. German $\mathrm{PPH}$ study group. J Am Coll Cardiol 2000; 35: 176-182.

53. Olschewski H, Ghofrani HA, Schmehl $\mathrm{T}$, et al. Inhaled iloprost to treat severe pulmonary hypertension. An uncontrolled trial. German PPH Study Group. Ann Intern Med 2000; 132: 435-443.

54. Hoeper MM, Schwarze M, Ehlerding S, et al. Longterm treatment of primary pulmonary hypertension with aerosolized iloprost, a prostacyclin analogue. $N$ Engl J Med 2000; 342: 1866-1870.

55. Olschewski H, Ghofrani HA, Walmrath $\mathrm{D}$, et al.
Inhaled prostacyclin and iloprost in severe pulmonary hypertension secondary to lung fibrosis. Am J Respir Crit Care Med 1999; 160: 600-607.

56. Stewart DJ, Levy RD, Cernacek P, Langleben D. Increased plasma endothelin-1 in pulmonary hypertension: marker or mediator of disease? Ann Intern Med 1991; 114: 464-469.

57. Galiè N, Borgatti ML, Ussia GP, et al. Comparative relation of neurohormonal activation to hemodynamics in primary or precapillary secondary pulmonary hypertension. J Am Coll Cardiol 1995; 25: 40A.

58. Galiè N, Grigoni F, Bacchi-Reggiani L, et al. Relation of endothelin-1 to survival in patients with primary pulmonary hypertension. Eur J Clin Invest 1996; 26: Suppl. 1, 273.

59. Giaid A, Yanagisawa M, Langleben D, et al. Expression of endothelin-1 in the lungs of patients with pulmonary hypertension. N Engl J Med 1993; 328: 1732-1739.

60. Luscher TF, Barton M. Endothelins and endothelin receptor antagonists: therapeutic considerations for a novel class of cardiovascular drugs. Circulation 2000; 102: 2434-2440.

61. Hill NS, Warburton RR, Pietras L, Klinger JR. Nonspecific endothelin-receptor antagonist blunts monocrotaline-induced pulmonary hypertension in rats. J Appl Physiol 1997; 83: 1209-1215.

62. Galie N, Hinderliter AL, Torbicki A, et al. Effect of the oral endothelin receptor antagonist bosentan on echocardiographic and Doppler measures in patients with pulmonary arterial hypertension. $J$ Am Coll Cardiol 2002; 39: 224A.

63. Wu-Wong JR. Sitaxsentan (ICOS-Texas Biotechnology). Curr Opin Investig Drugs 2001; 2: 531-536.

64. Kirchengast M. Endothelin receptor blockade and in-stent restenosis. J Cardiovasc Pharmacol 2001; 38: Suppl. 2, S31-S34.

65. Moncada S, Higgs A. The L-arginine-nitric oxide pathway. N Engl J Med 1993; 329: 2002-2012.

66. Mehta S, Stewart DJ, Langleben D, Levy RD. Shortterm pulmonary vasodilation with L-arginine in pulmonary hypertension. Circulation 1995; 92: 1539 1545.

67. Nagaya N, Uematsu M, Oya H, et al. Short-term oral administration of L-arginine improves hemodynamics and exercise capacity in patients with precapillary pulmonary hypertension. Am J Respir Crit Care Med 2001; 163: 887-891.

68. Weimann $\mathrm{J}$, Ullrich R, Hromi $\mathrm{J}$, et al. Sildenafil is a pulmonary vasodilator in awake lambs with acute pulmonary hypertension. Anesthesiology 2000; 92: 1702-1712.

69. Prasad S, Wilkinson J, Gatzoulis MA. Sildenafil in primary pulmonary hypertension. N Engl J Med 2000; 343: 1342.

70. Abrams D, Schulze-Neick I, Magee AG. Sildenafil as a selective pulmonary vasodilator in childhood primary pulmonary hypertension. Heart 2000; 84: E4.

71. Vachiery JL, Hill N, Zwicke D, Barst R, Blackburn S, Naeije R. Transitioning from IV epoprostenol to subcutaneous treprostinil in pulmonary arterial hypertension. Chest 2002; 121: 1561-1565.

72. Ghofrani A, Wiedermann R, Schermuly R, et al. Long-term effectiveness of additional oral sildenafil for improvement of patients with severe pulmonary arterial hypertension treated with inhalative iloprost therapy. Am J Respir Crit Care Med 2002; 165: A411. 